\title{
Quando a janela define a condição de desempenho térmico em ambientes ventilados naturalmente: caso específico das edificações multifamiliares em Vitória, ES
}

\author{
When windows define the condition of thermal \\ performance in naturally ventilated environments: the \\ specific case of multifamily buildings in Vitoria, ES
}

\section{Edna Aparecida Nico-Rodrigues \\ Cristina Engel de Alvarez \\ Amábeli Dell Santo \\ Maria Beatriz Piderit}

\section{Resumo \\ A}

adoção de diretrizes para o condicionamento térmico passivo auxilia na minimização do consumo de energia de uma edificação, principalmente quando associada a componentes construtivos com características térmicas adequadas às estratégias previstas. Entre tais estratégias, para climas tropicais úmidos, a ventilação assume fundamental importância. Este trabalho tem por objetivo avaliar a influência da janela no desempenho térmico em edificações residenciais multifamiliares na cidade de Vitória, ES, considerando dois modelos de janelas com ênfase na ventilação natural. Foram estabelecidas três etapas: caracterização dos modelos usuais nas edificações multifamiliares; definição do método para análise do desempenho térmico em ambientes ventilados naturalmente com o modelo usual, considerando a frequência de desconforto térmico e os graus-hora de desconforto térmico para a estação do verão; e simulações com o software DesignBuilder. Para o diagnóstico final foi adotada a flutuabilidade entre a frequência de desconforto térmico e o grau-hora de desconforto térmico caracterizando o desempenho térmico do ambiente para o favorecimento do conforto térmico. A avaliação demonstrou que a janela usual em Vitória é ineficiente para a obtenção de conforto térmico considerando a ventilação natural como condicionamento térmico passivo.

Palavras-chaves: Ventilação natural. Tipos de janelas. Desempenho térmico. Simulações.

Edna Aparecida Nico-Rodrigues Universidade Federal do Espírito Vitória - ES - Brasil

Cristina Engel de Alvarez Universidade Federal do Espírito Santo Vitória - ES - Brasil

Amábeli Dell Santo Instituto Federal do Espírito Santo Colatina - ES - Brasil

Maria Beatriz Piderit Universidad del Bío-Bío Concepción - Chile

Recebido em 25/02/14 Aceito em 25/03/15

\section{Abstract}

The adoption of guidelines for the passive thermal conditioning assists in minimizing the energy consumption of a building, especially when associated with construction components with thermal characteristics appropriate to the planned strategies. Among these strategies, for humid tropical climates, the ventilation assumes fundamental importance. The aim of this study was to evaluate the influence of the window on thermal performance in multifamily residential buildings in the Vitória (ES) city, considering the two windows typology, with emphasis on natural ventilation. Three steps were established: Characterization of the usual typologies in multifamily buildings; Definition of the method for analysis of thermal performance in naturally ventilated environments with the usual typology, considering the frequency of thermal discomfort and the degrees hours of thermal discomfort for the summer season; and Simulations with software DesignBuilder. For the final diagnosis it was adopted the variation between the frequency of thermal discomfort and the degree/hour of thermal discomfort characterizing the thermal performance of the environment. The evaluation showed that the usual window in Vitória $(E S)$ is inefficient for obtaining thermal comfort, considering the natural ventilation as passive thermal conditioning.

Keywords: Natural ventilation. Types of windows. Thermal performance. Simulations.

NICO-RODRIGUES, E. A.; ALVAREZ, C. E. de; SANTO, A. D.; PIDERIT, M. B. Quando a janela define a condição de desempenho térmico em ambientes ventilados naturalmente: caso específico das edificações multifamiliares em Vitória, ES. Ambiente Construído, Porto Alegre,v. 15, n. 2, p. 7-23, abr./jun. 2015. ISSN 1678-8621 Associação Nacional de Tecnologia do Ambiente Construído. http: / / http://dx.doi.org/10.1590/s1678-86212015000200011 


\section{Introdução}

As decorrentes variações climáticas provenientes das alterações de temperatura, vento, umidade e insolação são fatores que interferem na obtenção do conforto térmico. Adotar diretrizes que consideram as relações entre o clima e os seres humanos é importante na definição de ambientes adequados às sensações dos usuários. Para Roaf, Fuentes e Thomas (2006), a história registrou que os processos tecnológicos conduziram à eliminação de elementos como venezianas, persianas, composição de sistemas de aberturas, aberturas maiores e outros que outrora foram criados pela necessidade de promover a renovação do ar interior através do aproveitamento da ventilação natural.

Os benefícios atribuídos ao uso dos condicionantes naturais foram valorizados como estratégias para reduzir o consumo de energia e melhorar as condições térmicas do ambiente, especialmente a partir da crise energética mundial da década de 70 do século XX (SORMAN; GIAMPIETRO, 2013). Destaca-se que a ventilação natural, desde a antiguidade, é uma técnica conhecida para o controle do conforto térmico dos ambientes em espaços de habitação (KIM; PARK, 2010).

Para Stavrakakis et al. (2012), o custo energético de operação de um edifício naturalmente ventilado é $40 \%$ menor do que um edifício com arcondicionado, sendo as estratégias para ventilação natural mais eficazes quando se tem melhor aproveitamento das condições locais, como a ventilação noturna.

Segundo Jonsson e Roos (2010), de toda a energia primária consumida no mundo, $30 \%$ a $40 \%$ são usados nos edifícios, observando-se que o setor da construção é o que oferece maior potencial para a melhoria da eficiência energética (GUSTAVSEN et al., 2010). As janelas, como componentes da edificação, representam em muitos casos a parte da edificação que possui menor isolamento térmico da envoltória e, portanto, são um elemento-chave para o alcance do menor consumo de energia em edifícios, sendo também as responsáveis por grande parte das perdas e ganhos de calor no ambiente.

Para Nicol e Humphreys (2002), a qualidade do ambiente interior nas edificações é fator importante no consumo de energia, na qualidade de vida do ocupante e na sustentabilidade, principalmente quando se analisa sob o enfoque da energia para o uso e operação da edificação. Essa qualidade é determinada pelas características físicas da envolvente, bem como pelas propriedades de seus componentes, que independem das condições transitórias exteriores (SADINENI; MADALA; BOEHM, 2011).

De acordo com Albatici e Passerini (2011), a importância da escolha adequada de modelos de janelas em relação aos condicionantes da região é um dos fatores responsáveis pelo maior ou menor consumo de energia na edificação e, paralelamente, ao conforto térmico do usuário. Entre esses fatores destacam-se a forma, o tipo de vidro e a área envidraçada. Os resultados apresentados por Nico-Rodrigues (2008) identificaram que a adoção de janelas sem elementos vazantes e bloqueadores da radiação solar tem desempenho desfavorável para o conforto térmico, quando se considera a ventilação natural como estratégia para o conforto térmico passivo.

As pesquisas em ambientes ventilados naturalmente têm sido intensificadas, demonstrando preocupação, principalmente em regiões de clima tropical, para edificações que maximizem o uso da ventilação natural como condicionante térmico passivo (SANTO; ALVAREZ; NICO-RODRIGUES, 2013). Dessa forma, o modelo de conforto adaptativo da ASHRAE 55 (AMERICAN..., 2004) vem sendo referência para a determinação de temperatura de conforto, como fator primordial para a definição da aceitabilidade térmica para o usuário, tendo como condicionante fundamental a temperatura do ar externo. Esse modelo possibilita verificar, por meio de simulação computacional, se uma proposta arquitetônica proporciona desejável conforto térmico, principalmente nas estações mais quentes, sem o uso de equipamentos mecânicos (HUMPHREYS; RIJAL; NICOL, 2013).

Adotando o modelo de conforto adaptativo, Sicurella, Evola e Wurtz (2012) propõem um método que utiliza abordagem estatística para mensurar as condições de conforto/desconforto no interior dos ambientes, utilizando um importante condicionante físico, a temperatura operativa, por meio de indicadores de frequência e intensidade de desconforto térmico.

Mermet (2005) afirma que a adoção de condicionantes naturais na definição de diretrizes para o conforto térmico significa também considerar os comportamentos aleatórios e, consequentemente, de difícil controle. Quando se analisa a ventilação natural, os elementos físicos não são os únicos a ser indicadores do conforto, sendo necessária a realização de simulação do funcionamento e do consequente desempenho dos elementos construtivos. 
Esta pesquisa foi realizada na cidade de Vitória, ES (LAT 20¹9'09' S e LONG 40²0'50' W), pertencente à região Sudeste do Brasil. Com base na classificação climática de Köppen, o clima de Vitória é tropical litorâneo com temperaturas médias entre $18{ }^{\circ} \mathrm{C}$ e $26{ }^{\circ} \mathrm{C}$, sendo mais elevadas no período do verão, e umidades relativas superiores a $50 \%$.

Segundo Lamberts, Dutra e Pereira (2004), a região possui um percentual de desconforto na ordem de $82 \%$ de horas do ano, sendo que $64 \%$ referem-se ao calor, e $18 \%$ referem-se ao frio, recomendando para o alcance do conforto térmico o aproveitamento da ventilação natural, que atenua o desconforto em até $61 \%$ das horas do ano, considerando as interseções entre estratégias. Ressalta-se que a cidade é beneficiada por ventos predominantes para o quadrante nordeste (NE).

Esse panorama justifica a necessidade de estudos mais aprofundados para o elemento janela enquanto componente de fundamental importância na obtenção de condições favoráveis para a melhoria do conforto térmico e do desempenho térmico dos ambientes. Sendo assim, a pesquisa propõe um estudo de caso na cidade de Vitória, ES, que objetiva avaliar a influência da janela no desempenho térmico de edificações residenciais multifamiliares, considerando dois modelos de janelas, com ênfase na ventilação natural como estratégia para a obtenção do conforto térmico.

O estudo busca demonstrar o desempenho térmico para um ambiente de longa duração (dormitório) em edificação multifamiliar ventilada naturalmente, considerando o comparativo entre dois tipos de janelas, um comumente utilizado na região e outro tipo de janela, com diretriz bioclimática, definida por Nico-Rodrigues (2008) como uma das opções para a melhoria das condições térmicas internas. É aplicada uma metodologia que avalia as variações da temperatura operativa no decorrer do dia, tendo como referência a temperatura de conforto.

\section{Metodologia}

A pesquisa foi estabelecida a partir de três etapas principais:

(a) levantamento de campo;

(b) avaliação do desempenho térmico em ambientes ventilados naturalmente com dois tipos de janelas; e

(c) simulações.

\section{Levantamento de campo}

A utilização do levantamento de campo teve como objetivo principal a determinação e a caracterização dos tipos de janelas que são utilizadas nas edificações multifamiliares, para a constatação do modelo mais usual na definição das condições de desempenho térmico em ambientes internos, priorizando o conforto térmico.

\section{Delineamento}

A área definida na região urbana de Vitória para o levantamento dos tipos de janelas em edificações residenciais multifamiliares considerou os seguintes critérios:

(a) locais com crescimento na área da construção civil;

(b) áreas com adensamento habitacional multifamiliar; e

(c) áreas com registros estatísticos de crescimento e investimento no setor habitacional.

Considerando os critérios estabelecidos, a área amostral teve como parâmetro de escolha a divisão territorial definida pelo Sindicato das Indústrias da Construção Civil do Espírito Santo (SindusconES) para a realização semestral do Censo Imobiliário, que corresponde às seguintes áreas:

(a) Região 01: Bento Ferreira, Praia do Suá e Santa Lúcia;

(b) Região 02: Praia do Canto, Barro Vermelho e Santa Helena;

(c) Região 03: Enseada do Suá;

(d) Região 04: Jardim da Penha;

(e) Região 05: Jardim Camburi; e

(f) Região 06 : Mata da Praia.

As regiões selecionadas constituem áreas com maiores possibilidades de crescimento no setor da construção civil, por possuírem áreas livres e terrenos com edificações unifamiliares, sendo potencialmente favoráveis a novos empreendimentos. A área compreende bairros com aproximadamente 60 anos de ocupação e é constituída por uma mescla de edificações recentes e antigas. Foram observados e contabilizados os tipos de janelas em todos os edifícios multifamiliares em uso, localizados na área amostral definida.

\section{Coleta de dados}

Para registro dos modelos foram consideradas somente as janelas localizadas nos dormitórios, selecionados por serem locais de longa 
permanência (PREFEITURA..., 1998), cuja condição de habitabilidade sugere maior rigor quando comparado a outros ambientes da edificação.

Para o levantamento dos tipos de janelas adotou-se o método de observação, auxiliado por um mapa da região e um quadro com os modelos e as características das janelas classificadas como as mais comercializadas em Vitória por NicoRodrigues (2008), e atualizado com o respectivo registro fotográfico e descritivo. Para a caracterização das janelas foram observadas as diferenças referentes ao sistema de abertura, ao modelo e ao tipo de material de seus componentes.

O elemento janela considerado para análise é composto de marco, formado por montantes e travessas; folhas, que consistem na parte fixa ou móvel da janela onde são fixados os panos; e os panos, que são os elementos destinados à vedação, geralmente constituídos por vidros, venezianas, persianas e outros (ABNT, 1989).

\section{Avaliação do desempenho térmico em ambientes ventilados naturalmente com o tipo de janela mais usual}

A pesquisa avaliou primeiramente o modelo de janela mais usual nas edificações multifamiliares, sendo referência no comparativo dos resultados do segundo modelo proposto. Os fatores principais de análise foram a temperatura operativa horária e a temperatura de conforto, definida no gráfico de conforto adaptativo da ASHRAE 55 (AMERICAN..., 2004), que utiliza a variação da temperatura média mensal externa e a porcentagem de aceitabilidade para a determinação dos valores máximos e mínimos da temperatura de conforto.
Foram utilizados os valores máximos de temperatura de conforto, ressaltando que a cidade de Vitória possui elevadas temperaturas na estação do verão, como descrito anteriormente, demonstrando a necessidade de ações para amenizar o desconforto devido às condições climáticas nesse período.

A análise dos resultados para a definição das condições de conforto do ambiente foi pautada no quantitativo de desconforto térmico referente ao tipo de janela avaliado, pois, para Lamberts, Dutra e Pereira (2004), as condições climáticas para Vitória definem percentuais elevados de horas de desconforto, podendo ser utilizada a ventilação natural como estratégia para amenizar o desconforto para o calor.

Para a definição das temperaturas máximas de conforto determinou-se a temperatura média mensal externa com a utilização de software específico. O simulador selecionado para esta pesquisa foi o DesignBuilder versão 3.1.0.068 Beta - DBSIM (DESIGNBUILDER, 2012), que adota o algoritmo do EnergyPlus v7.

Os dados de temperatura média mensal externa obtidos das simulações foram inseridos no gráfico de conforto adaptativo, obtendo-se o intervalo de temperatura de conforto para o mês em questão, considerando $90 \%$ de aceitabilidade (Figura 1). A escolha do percentual de aceitabilidade do usuário de $90 \%$ reforça a preocupação com a concepção projetual das edificações atuais e de seus componentes. Observa-se que a ASHRAE 55 também propõe o uso do percentual de $90 \%$ como condicionante para a obtenção de um padrão mais elevado de conforto térmico (AMERICAN..., 2004).

\section{Figura 1 - Exemplo da obtenção dos limites de temperatura de conforto de acordo com o índice de} aceitabilidade para $90 \%$ da população

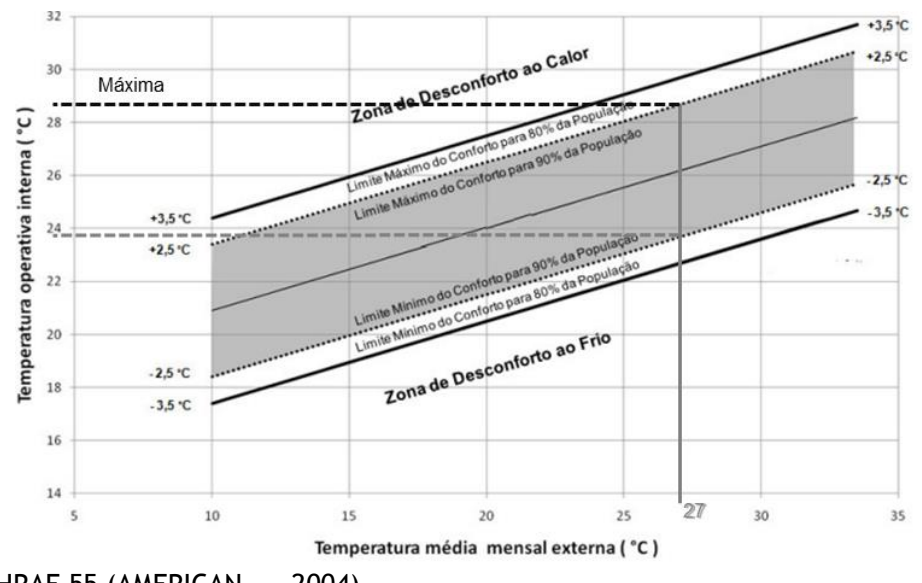

Fonte: adaptado da ASHRAE 55 (AMERICAN..., 2004). 
Para Roaf, Fuentes e Thomas (2006), a utilização da ventilação como meio para o resfriamento do ambiente está condicionada ao limite máximo da temperatura do ar externo em $35^{\circ} \mathrm{C}$; e Bittencourt e Cândido (2006) mencionam os estudos efetuados por Bowen em que o uso da ventilação para resfriamento pode ser uma condicionante indesejável quando a temperatura externa assume valores superiores a $34{ }^{\circ} \mathrm{C}$. Considerando as condições citadas, foram estabelecidos procedimentos estatísticos definindo uma amostra com dias válidos para a análise.

Adotou-se um modelo normal fundamentado em probabilidade e inferência estatística por meio dos valores de temperatura média do ar externo de todos os dias da estação do verão. O modelo adotado fundamenta-se no Teorema Central de Limites, em que uma amostra tende ao infinito (SILVA, 1998). Para a pesquisa optou-se por $99 \%$ de confiabilidade para a temperatura média diária dos dias da estação do verão, definindo o intervalo de confiança. Os valores fora do intervalo foram considerados outliers.

Para a avaliação do desempenho térmico do ambiente, considerando os dias definidos no intervalo de confiança, foram utilizados indicadores baseados na abordagem estatística para o conforto térmico proposto por Sicurella, Evola e Wurtz (2012), que analisaram as alterações da temperatura operativa durante as 24 horas do dia.

\section{Indicadores}

\section{Frequência de Desconforto Térmico - FDT}

A FDT equivale ao percentual de tempo, hora inteira, em que a temperatura operativa está acima do valor máximo de temperatura de conforto. Esse indicador quantifica as horas em desconforto na unidade de porcentagem durante determinado intervalo de tempo, e o valor máximo remete ao limite máximo do período. Nesta pesquisa, a proposta foi a de analisar períodos diários, ou seja, de 24 horas, correspondendo à frequência máxima de $100 \%$.

A FDT demonstra a frequência de desconforto durante um período para configurações, orientações e diferentes localizações de componentes construtivos, objetivando avaliar a eficácia das alternativas construtivas. Ela é mencionada na norma europeia EN 15251 (COMITÉ..., 2007), alicerçada no conceito de conforto adaptativo, e também nos Requisitos Técnicos da Qualidade para o Nível de Eficiência Energética de Edificações Comerciais (RTQ-C) (BRASIL, 2012b), pelo indicador de percentual de horas ocupadas em conforto (POC), com conceito análogo ao do FDT.

\section{Graus-horas de Desconforto Térmico - GhDT}

O GhDT é determinado pela diferença entre a temperatura operativa horária e a temperatura de conforto quando a temperatura operativa ultrapassa o valor definido da temperatura de conforto estabelecida para o mês em estudo. O valor máximo de referência adotado é resultante das simulações com o modelo de janela usual, obtendo-se o maior valor de GhDT, considerando todas as características do modelo e as condições climáticas.

Esse indicador auxilia na verificação das estratégias adotadas em relação ao desempenho térmico do ambiente, considerando que sua unidade está relacionada à temperatura e ao tempo. É mencionado na ABNT/CEE 191 (ABNT, 2014) e nos Requisitos Técnicos da Qualidade para o Nível de Eficiência Energética de Edificações Residenciais (RTQ-R) (BRASIL, 2012a), definido pelo indicador de graus-horas para resfriamento.

A avaliação dos dois indicadores possibilitou averiguar situações distintas para valores iguais de GhDT, conforme demonstrado na Figura 2. No Exemplo 1, tem-se a temperatura operativa superior à temperatura de conforto pelo período de $100 \%$, determinando uma sensação de desconforto moderada estável.

No Exemplo 2 verifica-se uma flutuação da temperatura operativa no intervalo de conforto, porém com período que excede ao limite de conforto, determinando uma sensação de desconforto maior e menos moderada. Para o Exemplo 3, a temperatura operativa está normalmente dentro do intervalo de conforto, porém há uma variação brusca da temperatura operativa, excedendo a temperatura de conforto, o que caracteriza uma sensação de desconforto breve, porém intensa.

Para Sicurella, Evola e Wurtz (2012), os exemplos descritos na Figura 2 ajudam a definir a melhor solução para a melhoria do conforto. Para o valor elevado de GhDT sem flutuação, como no Exemplo 1, é sugerida uma solução de melhoria em todo o edifício, porém para o Exemplo 3, onde se tem maior flutuação, o que denota desconforto intenso, a proposta é a utilização da ventilação mais intensa ou a adoção de sombreadores.

\section{Diagrama de flutuabilidade}

Para a análise dos indicadores FDT e GhDT adotou-se o diagrama de flutuabilidade proposto por Sicurella, Evola e Wurtz (2012), que facilita a 
avaliação e individualiza as melhorias de alguns parâmetros adotados como solução. O diagrama considera a avaliação da frequência em dois níveis: temporário e frequente; e a condição de intensidade para os graus-horas nos níveis leve e intenso (Figura 3).

A análise no diagrama de flutuabilidade possibilitou determinar a pior situação, com os valores mais elevados - de FDT $(100 \%)$ e do GhDT (referente ao maior valor de GhDT de todas as situações simuladas) -, e uma situação melhor, quando os indicadores tendem a zero. Os valores intermediários de FDT (FDT elevado e GhDT baixo) e para GhDT (GhDT elevado e FDT baixo) são ocasionados pelas alterações das temperaturas externas; pela direção, frequência e intensidade do vento durante as horas do dia; pela incidência da radiação solar na envolvente; pelas características do tipo de janela, localização, e mecanismos de direcionamento e controle do fluxo de ar; e pelas aberturas de saída.

\section{Simulações}

\section{Sítio, características e propriedades do modelo}

Para a análise das condições climáticas da cidade de Vitória foi adotado o arquivo climático TRY (Test Reference Year) referente ao período de 2000 a 2010 (LABORATÓRIO..., 2012). Para definir as temperaturas médias mensais de solo foram adotadas as médias das temperaturas do ar externo para cada mês (DESIGNBUILDER, 2009).

As condições de velocidade e direção do vento foram representadas nas Figuras $4 \mathrm{a}$ e $4 \mathrm{~b}$, observando-se a frequência de ocorrência dos dados para o mesmo período. Os resultados enfatizaram a predominância do vento no quadrante $\mathrm{NE}$, com maior frequência de velocidade em 3,6-5,7 m/s, o que possibilita o uso da ventilação natural como recurso para amenizar o desconforto térmico, principalmente nos meses mais quentes.

Figura 2 - Análise das flutuações da temperatura operativa para o período de 24 horas

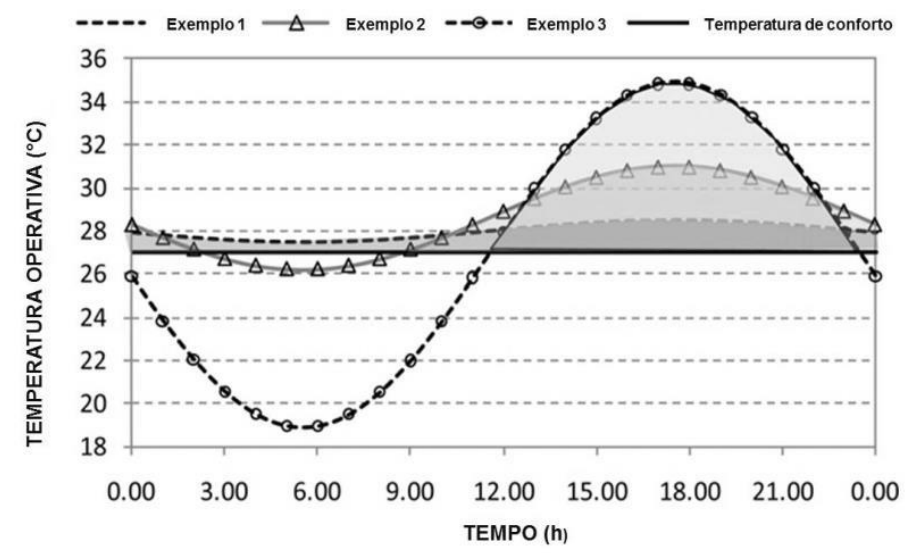

Fonte: adaptado de Sicurella, Evola e Wurtz (2012).

Figura 3 - Diagrama de flutuabilidade para FDT e GhDT

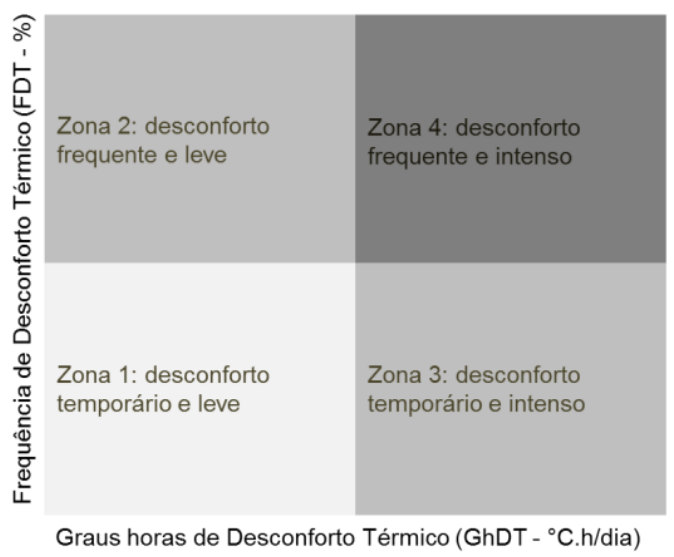

Fonte: adaptado de Sicurella, Evola e Wurtz (2012). 
Figura 4 - Frequência de ocorrência e direção dos ventos referentes ao período de 2000 a 2010 para a cidade de Vitória

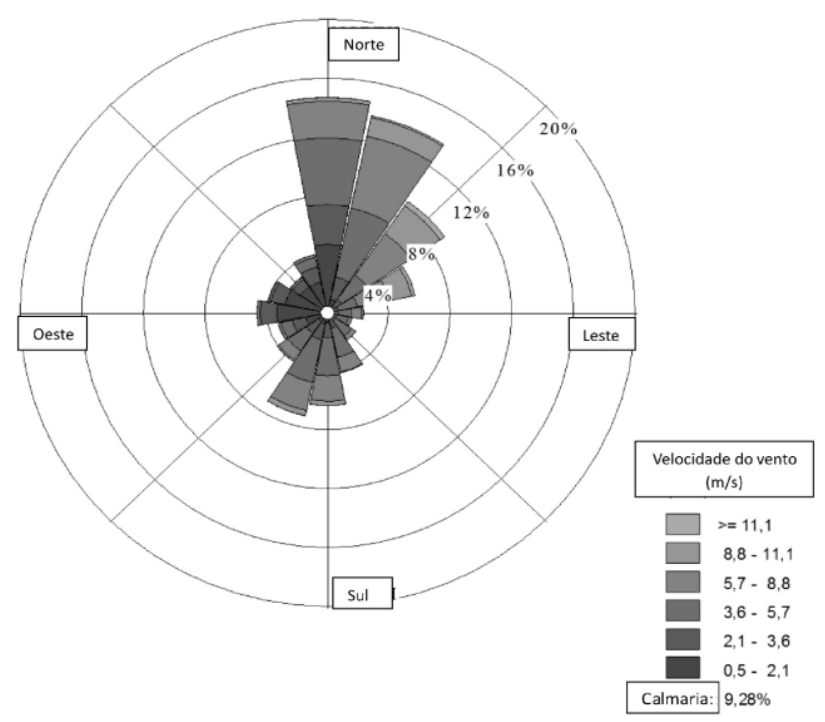

(a) Direção do vento

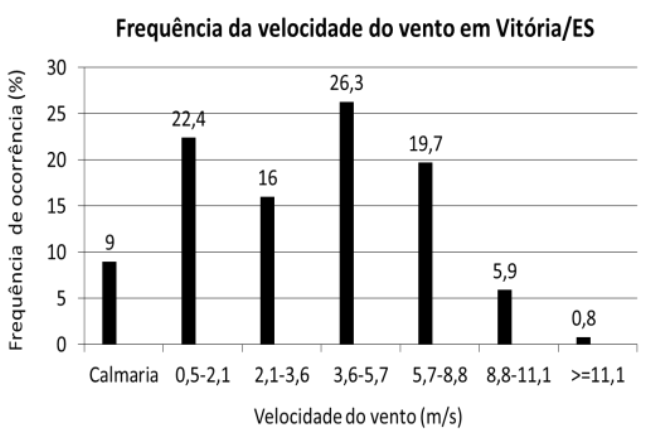

(b) Frequência da velocidade do vento

Fonte: Mattiuzzi e Marchioro (2012).

A tipologia arquitetônica adotada como modelo para simulação possui cinco pavimentos, sendo o térreo de pilotis, e os apartamentos tipo constituídos de dois dormitórios e divididos espacialmente em sala de estar, cozinha, área de serviço e banheiro, com aproximadamente $70 \mathrm{~m}^{2}$, destacando-se ser a tipologia mais comercializada na região (SINDICATO..., 2011). Observa-se ainda que no RTQ-R (BRASIL, 2012a) foi definido um modelo de edificação para simulação com as mesmas características citadas, reiterando a escolha do modelo para esta investigação (Figura 5).

Foram adotados os valores referenciais das propriedades térmicas dos componentes construtivos relacionados à envoltória da edificação utilizados em Vitória, assim como as características da vestimenta e tipo de atividade realizada pelo usuário definidos pela NBR 15220-3 (ABNT, 2005) e pela NBR 15575-4 (ABNT, 2013b), apresentados na Tabela 1. A eleição do tipo de vestimenta e de atividade está relacionada com o período do verão, considerando ser a estação mais preocupante para a obtenção de conforto térmico.

As dimensões das janelas seguem a NBR 15575-4 (ABNT, 2013b), ou seja, equivalem a 8\% da área de piso para a região Sudeste. Foram avaliados dois modelos de janelas: um comumente utilizado, nomeado de M1; e o segundo modelo definido como M2, considerando as mesmas dimensões, porém com panos em venezianas e dispositivo de sombra na largura da janela.

A janela está localizada na parede externa, com peitoril de 1,00 m de altura. A porta do ambiente é o segundo elemento para permitir a ventilação cruzada, considerando que também as frestas existentes possibilitam a circulação do ar através da ventilação cruzada, quando elas estão fechadas.

A configuração adotada no DesignBuilder para a ventilação foi o modelo de ventilação calculada, sendo a ventilação e as taxas de infiltração do fluxo de ar calculadas com base nas dimensões das aberturas, operação das janelas e flutuabilidade das pressões do vento.

As simulações foram efetuadas no dormitório 2, localizado no $1^{\circ}$ pavimento (sobre o piso do pilotis), em um pavimento intermediário e no último pavimento. Foi simulada a rotação do edifício posicionando-se a janela para as orientações norte, sul, leste e oeste, considerando o período do verão (21/dez. a $21 /$ mar.), por ser o mais quente da região, conforme definido pela NBR 15575-1 (ABNT, 2013a). 
Figura 5 - Modelo de edificação multifamiliar

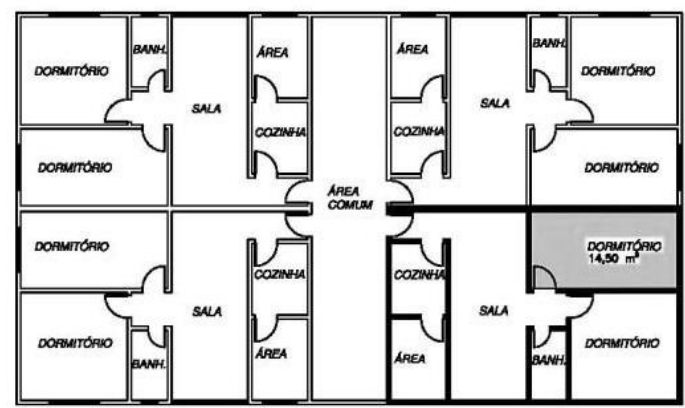

PLANTA BAIXA

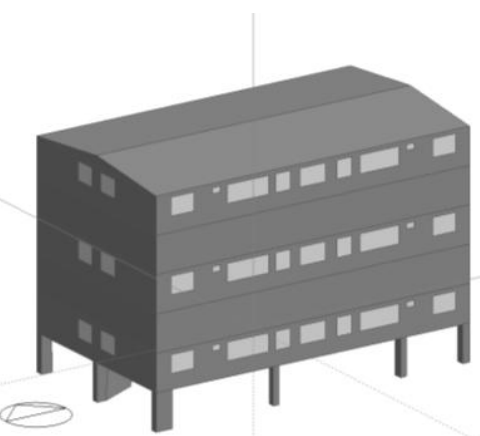

Fonte: DesignBuilder (2012).

Tabela 1 - Detalhamento das camadas das paredes e lajes com as propriedades dos materiais

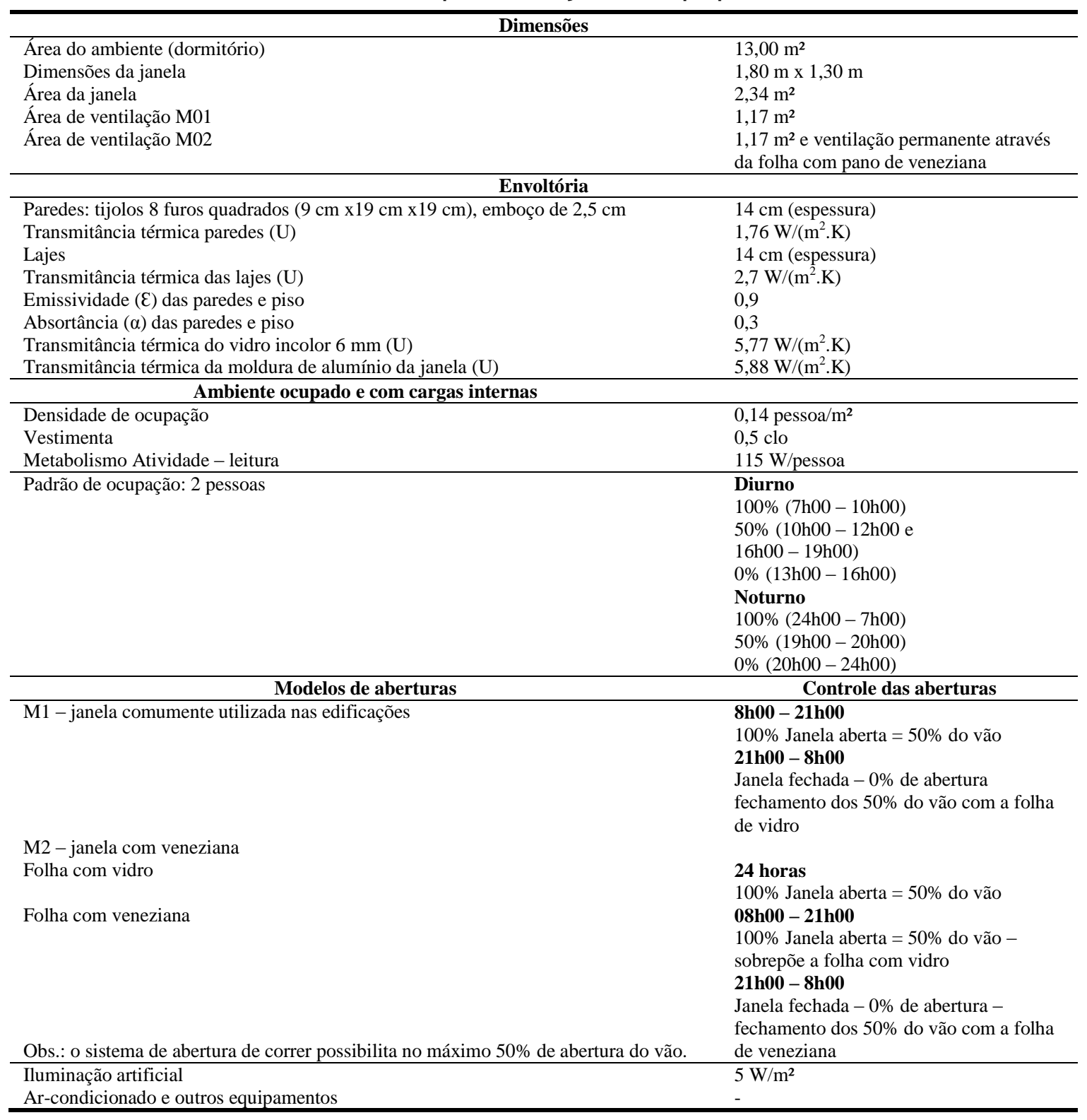

Fonte: elaborado a partir da NBR 15575-4 (ABNT, 2013b).

14 Nico-Rodrigues, E. A.; Alvarez, C. E.; Santo, A. D.; Piderit, M. B. 


\section{Resultados e discussões}

\section{Caracterização das janelas}

Para a identificação dos modelos mais usuais de janelas na região foram observadas 1.999 unidades de edificações multifamiliares que categorizaram 23 tipos de janelas diferentes. As diferenças observadas referem-se apenas ao modelo de janela, e cada modelo tem componentes distintos, tais como material (alumínio, PVC ou madeira), cor do vidro, cor do alumínio e sistema de abertura e composição de folhas. A Tabela 2 sintetiza o quantitativo das diferentes janelas registradas em cada bairro e, consequentemente, o quantitativo de edificações multifamiliares em uso.

Para melhor identificação das diferentes janelas, foram adotadas abreviações para caracterizar cada modelo, como Modelo A - MA; Modelo B - MB e assim por diante para todos os outros modelos observados. A Figura 6 representa os percentuais de utilização dos 7 (sete) tipos de janelas com maior representatividade nas edificações observadas (MA; MB; MC; MD; ME; MF e MG), resultando em $91,85 \%$. Os $8,15 \%$ restantes correspondem aos outros 16 (dezesseis) modelos (MH, MI, MJ, MM e outros), que compuseram o total final de 23 modelos de janelas diferentes constatadas nas edificações multifamiliares registradas no levantamento.

$\mathrm{O}$ resultado demonstrou que o tipo de janela mais utilizado nas edificações residenciais multifamiliares é o MA, feito de alumínio, caracterizado com marco simples (montantes e travessas) e duas folhas com panos em vidros, no sistema de correr e sem dispositivo de sombra. Observou-se que um grande percentual de edificações possui as portas-janelas dos dormitórios voltadas para espaços avarandados e que a maioria opta pelo fechamento total da varanda, com vidros e ferragens e no sistema de abertura do tipo camarão.

Tabela 2 - Quantificação das janelas e modelos

\begin{tabular}{c|c|c|c|c|c|c|c|c|c|c}
\hline REGIÃO & \multicolumn{3}{|c|}{$\mathbf{0 1}$} & \multicolumn{3}{|c|}{$\mathbf{0 2}$} & $\mathbf{0 3}$ & $\mathbf{0 4}$ & $\mathbf{0 5}$ & $\mathbf{0 6}$ \\
\hline BAIRRO & $\begin{array}{c}\text { Bento } \\
\text { Ferreira }\end{array}$ & $\begin{array}{c}\text { Praia } \\
\text { do } \\
\text { Suá }\end{array}$ & $\begin{array}{c}\text { Santa } \\
\text { Lúcia }\end{array}$ & $\begin{array}{c}\text { Praia } \\
\text { do } \\
\text { Canto }\end{array}$ & $\begin{array}{c}\text { Praia de } \\
\text { Santa } \\
\text { Helena }\end{array}$ & $\begin{array}{c}\text { Barro } \\
\text { Vermelho }\end{array}$ & $\begin{array}{c}\text { Enseada } \\
\text { do Suá }\end{array}$ & $\begin{array}{c}\text { Jardim } \\
\text { da } \\
\text { Penha }\end{array}$ & $\begin{array}{c}\text { Jardim } \\
\text { Camburi }\end{array}$ & $\begin{array}{c}\text { Mata } \\
\text { da } \\
\text { Praia }\end{array}$ \\
\hline $\begin{array}{c}\text { QTDADE. } \\
\text { DE } \\
\text { JANELAS }\end{array}$ & 50 & 06 & 19 & 241 & 76 & 40 & 07 & 863 & 560 & 136 \\
\hline TIPOS & 09 & 04 & 04 & 18 & 08 & 08 & 03 & 20 & 14 & 13 \\
\hline
\end{tabular}

Figura 6 - Resultado dos modelos de janelas das edificações multifamiliares de Vitória

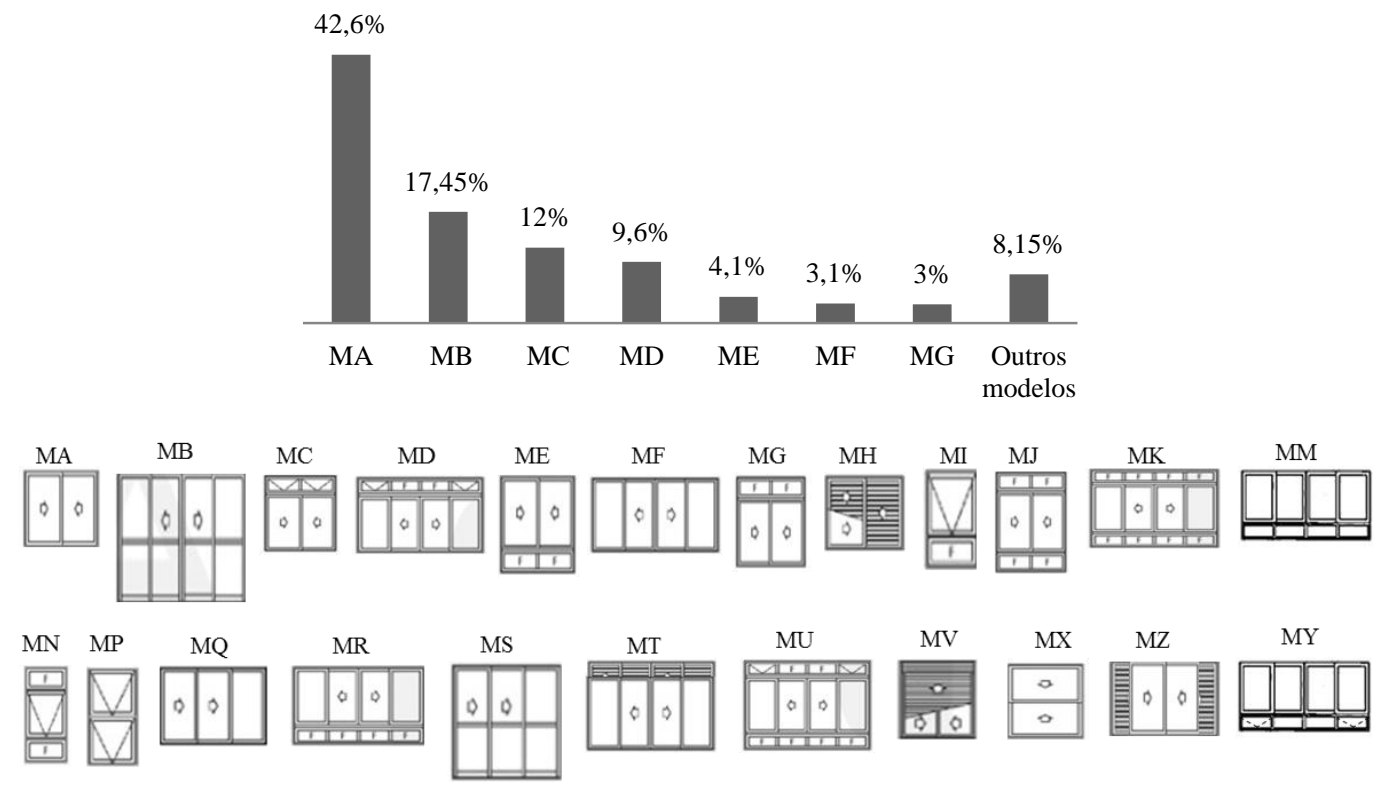

Quando a janela define a condição de desempenho térmico em ambientes ventilados naturalmente: caso específico das edificações multifamiliares em Vitória, ES 
As cores de vidro mais utilizadas nas esquadrias foram o incolor e o fumê, encontrando-se também vidros nas cores verde e bronze. A predominância do material dos quadros e folhas foi o alumínio, que está relacionado, entre outros fatores, ao custo, facilidade de manutenção, durabilidade e adequabilidade em relação à concepção volumétrica das tipologias arquitetônicas. Ressalta-se que Vitória é uma ilha e que sua proximidade com o mar induz à utilização de materiais com maior resistência à névoa salina.

\section{Determinação dos condicionantes}

Os resultados simulados definiram as médias mensais das temperaturas do ar externo, considerando o arquivo climático TRY da cidade de Vitória, posteriormente plotadas no gráfico de conforto adaptativo da ASHRAE 55 (AMERICAN..., 2004) para a determinação das temperaturas de conforto mínima e máxima. Para a pesquisa em questão foram adotadas as temperaturas máximas de conforto (Tabela 3).

Para a definição dos dias válidos para análise, os resultados fundamentados na probabilidade $\mathrm{e}$ inferência estatística definiram os valores do intervalo para a estação do verão (Tabela 4), determinando os dias para análise.

\section{Resultados das simulações}

As simulações possibilitaram avaliar o desempenho térmico do ambiente de acordo com o tipo de janela, considerando a média mensal da temperatura externa e a temperatura operativa horária como fatores determinantes de desconforto térmico, destacando-se a adoção da ventilação natural como estratégia para o conforto térmico.

Inicialmente foi simulado o ambiente com o modelo MA resultante do levantamento de campo, nomeado como $\mathrm{M} 1$, tendo os resultados das temperaturas operativas referentes a cada pavimento e em cada orientação sido submetidos a procedimentos estatísticos para definir os valores de GhDT diário, determinando o maior valor como referência de análise comparativa para o segundo modelo de janela, M2 (Tabela 5).

O valor máximo de referência do GhDT para o período da estação do verão estabelecido foi:

(a) $\mathrm{FDT}=100 \%$ ou $528 \mathrm{~h}$; e

(b) GhDT, o valor máximo foi de $46,38^{\circ} \mathrm{C} \cdot \mathrm{h} / \mathrm{dia}$.

Tabela 3 - Médias mensais das temperaturas do ar externo e o intervalo de temperatura de conforto térmico baseado no modelo de conforto adaptativo da ASHRAE 55

\begin{tabular}{c|cc}
\hline Meses & $\begin{array}{c}\text { Média mensal da temperatura do } \\
\text { ar externo }\left({ }^{\circ} \mathbf{C}\right)\end{array}$ & $\begin{array}{c}\text { Intervalo de temperatura de conforto } \\
\text { Min. }- \text { Máx. }\left({ }^{\circ} \mathbf{C}\right)\end{array}$ \\
\hline Dezembro & 26,86 & $23,61-28,61$ \\
Janeiro & 26,35 & $23,45-28,45$ \\
Fevereiro & 25,76 & $23,27-28,27$ \\
Março & 26,65 & $23,55-28,55$ \\
\hline
\end{tabular}

Tabela 4 - Dias definidos pelo intervalo de confiança para o período do verão

\begin{tabular}{|c|c|c|c|c|}
\hline \multicolumn{5}{|c|}{ Intervalo de temperatura para a estação do verão $-25,97^{\circ} \mathrm{C}$ a $26,77^{\circ} \mathrm{C}$} \\
\hline \multirow{12}{*}{ 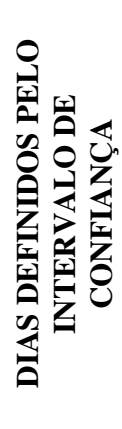 } & Dezembro & Janeiro & Fevereiro & Março \\
\hline & 21 & 05 & 01 & 01 \\
\hline & & 06 & 05 & 03 \\
\hline & & 17 & 08 & 06 \\
\hline & & 22 & 09 & 09 \\
\hline & & & 10 & 10 \\
\hline & & & 19 & 11 \\
\hline & & & 20 & 17 \\
\hline & & & 21 & \\
\hline & & & 25 & \\
\hline & & & 26 & \\
\hline & & Total d & $\operatorname{dias}=52$ & \\
\hline
\end{tabular}

16 Nico-Rodrigues, E. A.; Alvarez, C. E.; Santo, A. D.; Piderit, M. B. 
Tabela 5 - Valores totais de GhDT de cada orientação. Em destaque o valor adotado como referência

\begin{tabular}{l|llll}
\hline \multicolumn{4}{|c}{ ESTAÇÃO DO VERÃO } \\
\hline Valor de & SUL & OESTE & NORTE & LESTE \\
\cline { 2 - 5 } referência & $08 / \mathrm{fev}-1^{\circ} \mathrm{pav}$ & $08 / \mathrm{fev}-1^{\circ} \mathrm{pav}$ & $09 / \mathrm{fev}-1^{\circ} \mathrm{pav}$ & $11 / \mathrm{mar}-1^{\circ} \mathrm{pav}$ \\
do GhDT & $\mathrm{GhDT}=42,54^{\circ} \mathrm{C} . \mathrm{h} / \mathrm{dia}$ & $\mathrm{GhDT}=46,38^{\circ} \mathrm{C} . \mathrm{h} / \mathrm{dia}$ & $\mathrm{GhDT}=40,14^{\circ} \mathrm{C} . \mathrm{h} / \mathrm{dia}$ & $\mathrm{GhDT}=29,10^{\circ} \mathrm{C} . \mathrm{h} / \mathrm{dia}$ \\
\hline
\end{tabular}

A primeira série de resultados (Figura 7 - 1a, 1b, 1c e 1d) objetivou analisar e definir as condições internas do ambiente com o uso do modelo de janela M1. A segunda série de gráficos (Figura 7 $2 \mathrm{a}, 2 \mathrm{~b}, 2 \mathrm{c}, 2 \mathrm{~d})$ demonstrou os resultados do modelo M2. Os valores de FDT e GhDT obtidos para cada dia foram plotados no diagrama de flutuabilidade, caracterizando as condições térmicas finais do ambiente dormitório para o conforto térmico. Ressalta-se que o diagrama de flutuabilidade demonstra as situações diárias, sendo a melhor condição aquela que converge para a origem.

Os resultados das simulações de desempenho da janela demonstraram que o modelo comumente utilizado nas edificações multifamiliares, o modelo M1 (Figura 7 - 1a, 1b, 1c e 1d), determinou para o período do verão ambiente desconfortável para todas as orientações e para os três pavimentos avaliados. Observou-se que em todos os pavimentos e orientações os resultados de FDT e GhDT indicaram três níveis de sensações de desconforto:

(a) dias com desconforto térmico temporário e leve, quando as diferenças de GhDT foram menores em um curto período do dia, culminando em um percentual também menor de FDT;

(b) dias com desconforto leve, porém frequente, configurando um GhDT menor e um FDT com percentuais elevados; e

(c) desconforto intenso e frequente, demonstrando valores elevados de GhDT e de FDT.

Os resultados das simulações para o modelo M2 (Figura 7 - 2a, 2b, 2c e 2d) determinaram para o período do verão ambiente desconfortável em todas as orientações e nos três pavimentos avaliados, porém na análise comparativa com o modelo M1 ficaram evidenciadas melhorias substanciais nas condições internas do ambiente. Observou-se que em todos os pavimentos e orientações os resultados de FDT e GhDT indicaram dois níveis de sensações de desconforto:

(a) um percentual maior de dias com desconforto térmico leve e temporário, quando os valores de GhDT foram menores em um curto período do dia, culminando no percentual menor de FDT; e

(b) um percentual menor de dias com desconforto leve e frequente, configurando temperaturas mais elevadas por um período maior no dia, ou seja, FDT com percentuais maiores.

Observando a análise por orientação do modelo M1, constatou-se o seguinte:

(a) orientação leste (Figura 7 - 1a): os valores de temperatura se mantiveram constantemente acima do limite de conforto, com flutuações durante as horas do dia, classificando o desconforto como de intensidade leve para moderada, e um FDT temporário para frequente. Essa avaliação sugere a adoção de diretrizes construtivas diferenciadas em relação ao tamanho da abertura, tipo de vidro, elementos permeáveis à ventilação, sombreadores, entre outros recomendados que amenizem a frequência do desconforto térmico para essa orientação;

(b) orientação norte (Figura 7 - 1b): as diferenças de temperaturas, o que equivale ao GhDT, se mantiveram acima do limite de conforto, com pouca flutuação durante todo o período, ou seja, a frequência de desconforto térmico em $100 \%$ das horas do dia foi observada em quase todo o período. O desempenho do ambiente para esta orientação determinou um nível de desconforto com grande intensidade, classificado assim como intenso e frequente. As diretrizes sugeridas para situações semelhantes estão relacionadas à melhoria em todo o edifício, com a inserção de componentes para amenizar a incidência da radiação solar e maximizar a ventilação natural; e

(c) orientações oeste e sul (Figura 7 - 1c e 1d): constatou-se que os ambientes apresentaram comportamento semelhante para as duas orientações. O GhDT possui flutuações moderadas e com algumas particularidades observadas nos diferentes pavimentos. Para o desempenho do ambiente nessas orientações obteve-se um nível de desconforto para alguns dias classificado como leve e temporário, enquanto em outros dias, a condição de sensação leve e frequente e um percentual de intensidade de frequência mais elevado. As intervenções para melhorias de conforto podem ocorrer tanto nas janelas e em seus componentes como ao nível do edifício, com a adoção de componentes construtivos que direcionem a ventilação natural.

A análise dos resultados do modelo M2 (Figura 7 $2 \mathrm{a}, 2 \mathrm{~b}, 2 \mathrm{c}$ e $2 \mathrm{~d})$ definiu ambientes com melhor desempenho para o conforto térmico quando 
comparado com o modelo M1. Quanto ao comparativo entre as orientações do modelo M2, observou-se que os resultados se mantiveram muito semelhantes, com pequenas diferenças percentuais, demonstrando que a orientação oeste apresentou melhor condição de desempenho.

Ressalta-se que em todas as orientações os valores de temperatura operativa se mantiveram em alguns períodos acima do limite de conforto e em outros períodos dentro do limite de conforto, classificando o desconforto para as orientações como sendo de intensidade leve e temporária, com alguns períodos para frequente. Destaca-se que o aumento do FDT de temporário para frequente foi devido às alterações diárias da temperatura, que interferiram nas condições internas do ambiente.

A análise do somatório do FDT e do GhDT para cada modelo de janela demonstrou que a adoção de componentes de ventilação e de proteção da radiação para a janela resultou em temperaturas operativas com valores menores, culminando na diminuição do percentual de horas de desconforto e na quantidade de graus-horas (Figura 7 - 1a, 1b, $1 c, 2 a, 2 b$ e $2 c)$.

Figura 7 - Diagramas de flutuabilidade da estação do verão

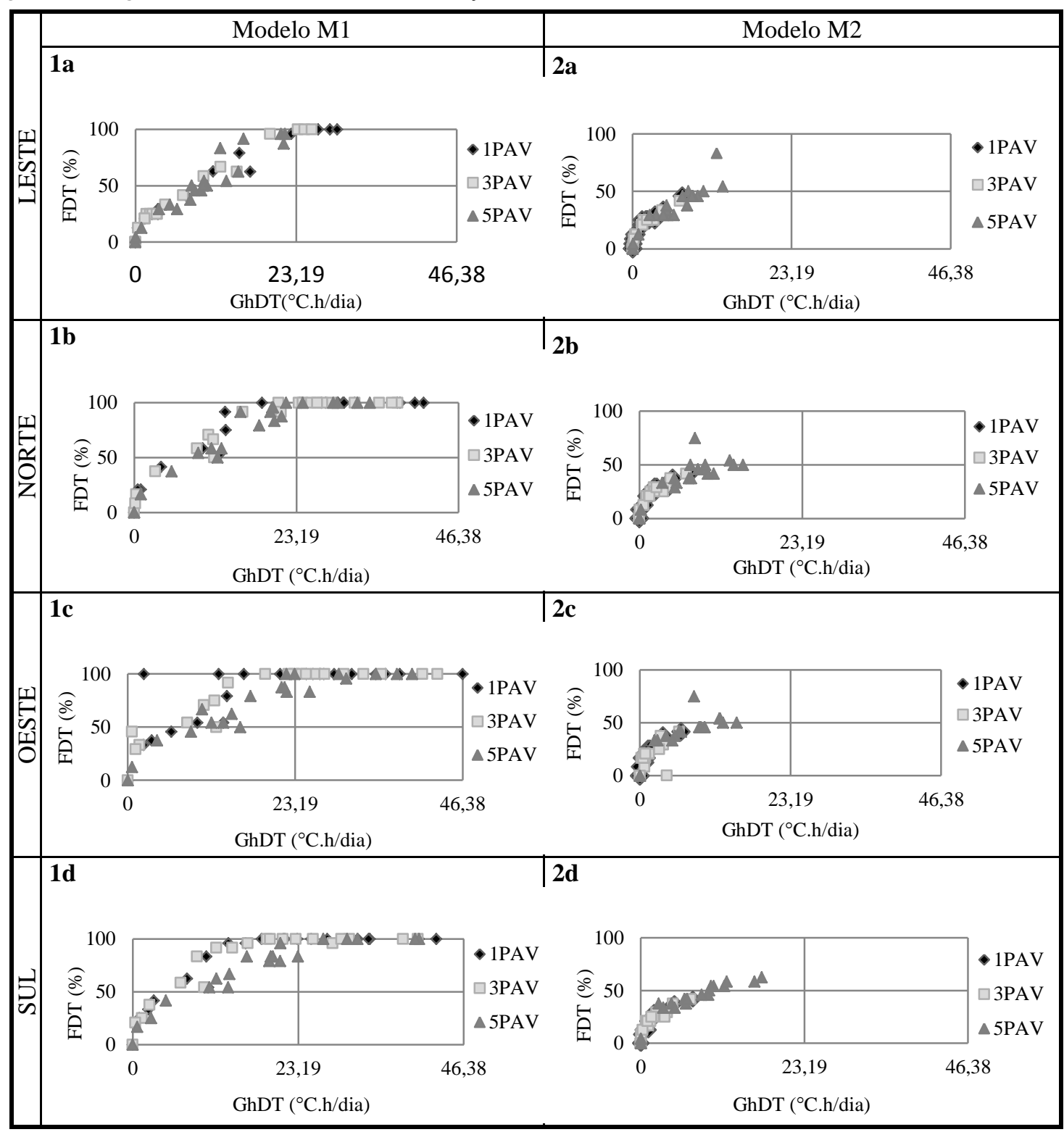

18 Nico-Rodrigues, E. A.; Alvarez, C. E.; Santo, A. D.; Piderit, M. B. 
No modelo M1, as diferenças observadas, principalmente para as orientações norte, oeste e sul, estão relacionadas ao somatório de GhDT e de FDT do período, em que é possível identificar as diferenças por pavimento e por orientação (Figura 8 - 1a, 1b e 1c). Nestas orientações, o melhor desempenho foi no $5^{\circ}$ pavimento, que obteve valores para o FDT de $66,8 \%$ na orientação sul (o mínimo atingido nestas orientações), correspondendo a $353 \mathrm{~h}$ do período do verão, e com o GhDT de $377,99{ }^{\circ} \mathrm{C} . \mathrm{h} / \mathrm{dia}$, com moderada flutuação e com sensação de desconforto breve e intensa.

A orientação leste definiu as melhores condições quando comparada às demais orientações, e o $1^{\circ}$ pavimento obteve aproximadamente $39 \%$ do período em condição de desconforto, ou seja, o equivalente a $207 \mathrm{~h}$ do verão, com uma ocorrência de GhDT equivalente a $176,5{ }^{\circ} \mathrm{C} . h / d i a$, caracterizando alta flutuação da temperatura, porém com valores de GhDT moderados durante o dia (Figura 8 - 1a). Verifica-se ainda que há uma amplitude térmica entre os pavimentos que pode ser percebida pelos usuários durante o dia.

Os valores obtidos no somatório de GhDT e FDT (Figura 8) para as orientações oeste e sul foram em decorrência dos seguintes fatores:

(a) para a latitude da cidade de Vitória, a orientação sul possui insolação durante a maior parte dos meses do verão e durante todo o período do dia, com as alturas solares e azimutes determinando ângulos maiores de incidência solar, diferentemente da orientação oeste, em que a insolação acontece no período vespertino, com as alturas solares e azimutes determinando os ângulos menores de incidência no plano vertical da fachada, o que implica uma absorção mais intensa do calor; e

(b) frequência do vento para os quadrantes nordeste e norte (Figura 4a e 4b), resultando em ambientes menos confortável nas orientações sul e oeste. Este fator também definiu melhores condições de desempenho para o $5^{\circ}$ pavimento. Mesmo a janela não estando posicionada para as direções privilegiadas pelos ventos frequentes, ressalta-se que a altura do pavimento possibilitou maior circulação do ar, melhorando as condições internas do ambiente.

Para a orientação leste o desempenho do ambiente foi melhor, como mencionado anteriormente, pois a incidência da radiação solar acontece no período matutino e a ventilação para esta orientação é beneficiada pela frequência dos ventos nordeste e norte.
No desempenho registrado para a orientação norte, mesmo tendo a incidência solar em parte do período analisado (23/fev. a 22/mar.), as alturas solares, bem como os azimutes solares incide mais obliquamente no plano vertical da fachada, aumentando a absorção de calor.

O modelo M2 (Figura 8 - 2a, 2b e 2c) definiu condições mais favoráveis ao conforto térmico, diminuindo aproximadamente em $50 \%$ as horas em desconforto e o quantitativo de graus-horas para todas as orientações e pavimentos. Observa-se que os pavimentos que obtiveram resultados melhores foram o $1^{\circ}$ e $\quad$ o $3^{\circ}$ em todas as orientações, sendo a oeste a que indicou melhores condições para o $3^{\circ}$ pavimento, diminuindo de $75,2 \%$ de horas no modelo M1 para $12,5 \%$ de horas em desconforto para o modelo M2, resultando também na diminuição dos graus-horas de $408,16^{\circ} \mathrm{C} . h /$ dia para $26,1^{\circ} \mathrm{C} . \mathrm{h} /$ dia. Destaca-se a influência do dispositivo de sombra no desempenho térmico, que ameniza as condições térmicas internas no período de temperaturas mais elevadas.

O pior desempenho foi para a orientação sul, no $5^{\circ}$ pavimento, com uma frequência de $35,8 \%$ do período em desconforto, e um maior GhDT na orientação norte, com $146,18^{\circ} \mathrm{C} . \mathrm{h} / \mathrm{dia}$, ocasionado por pequenas variações das temperaturas.

Os aspectos que definiram as condições térmicas diferentes entre o $5^{\circ}$ pavimento com o modelo M1 e o $5^{\circ}$ pavimento com o modelo M2 estão relacionados à ventilação e à incidência solar na cobertura. No edifício com o modelo M1 de janela, a interferência da velocidade do vento nos pavimentos mais altos foi decisiva para definir o $5^{\circ}$ pavimento com melhor desempenho, mesmo tendo a interferência da cobertura.

No edifício com o modelo M2 de janela, os dispositivos de sombra foram fatores responsáveis para melhorar as condições de desempenho no $1^{\circ} \mathrm{e}$ $3^{\circ}$ pavimento, definindo para o $5^{\circ}$ pavimento a pior condição e destacando que a incidência solar na cobertura interferiu nas condições de desempenho do ambiente.

Outro fator que intensificou o desconforto verificado está relacionado à ventilação noturna no ambiente, considerando que o tipo de janela mais comumente utilizada nas edificações multifamiliares, modelo M1, não possui nenhum componente que possibilite a renovação do ar quando fechada. $\mathrm{O}$ fechamento noturno das janelas para a realidade da região considerada está vinculado a dois fatores fundamentais: segurança e entrada de insetos. No entanto, para este estudo essas situações foram consideradas, visto que telas 
e grades não são soluções adotadas com frequência nos bairros considerados.

Os resultados com o modelo $\mathrm{M} 1$ revelaram a necessidade de intervenções significativas para a melhoria do desempenho térmico do ambiente, como, por exemplo, a adoção de sombreadores, elementos vazantes, alterações nas dimensões e na localização, e utilização de sistemas de aberturas diferenciados.

O modelo M2 demonstrou que a utilização de dispositivos de sombra para a proteção da radiação solar e a utilização dos elementos vazantes foram fatores importantes para melhorar as condições internas do ambiente, destacando-se a frequência do vento no verão de $53,8 \%$ e um percentual insignificante da ausência de vento no período vespertino. Verificou-se ainda que a possibilidade de permitir a ventilação noturna foi um fator adicional que auxiliou na melhoria das condições de habitabilidade do ambiente.

Em síntese, pode-se afirmar que a utilização de soluções como o aumento da abertura, o direcionamento das janelas voltado para as melhores condições de ventilação e a inserção de componentes que auxiliem no sombreamento e na captação do vento são algumas das soluções adequadas para alcance de condições térmicas internas melhores, principalmente na estação do verão para a cidade de Vitória.

Figura 8 - Somatório de GhDT e FDT do período do verão

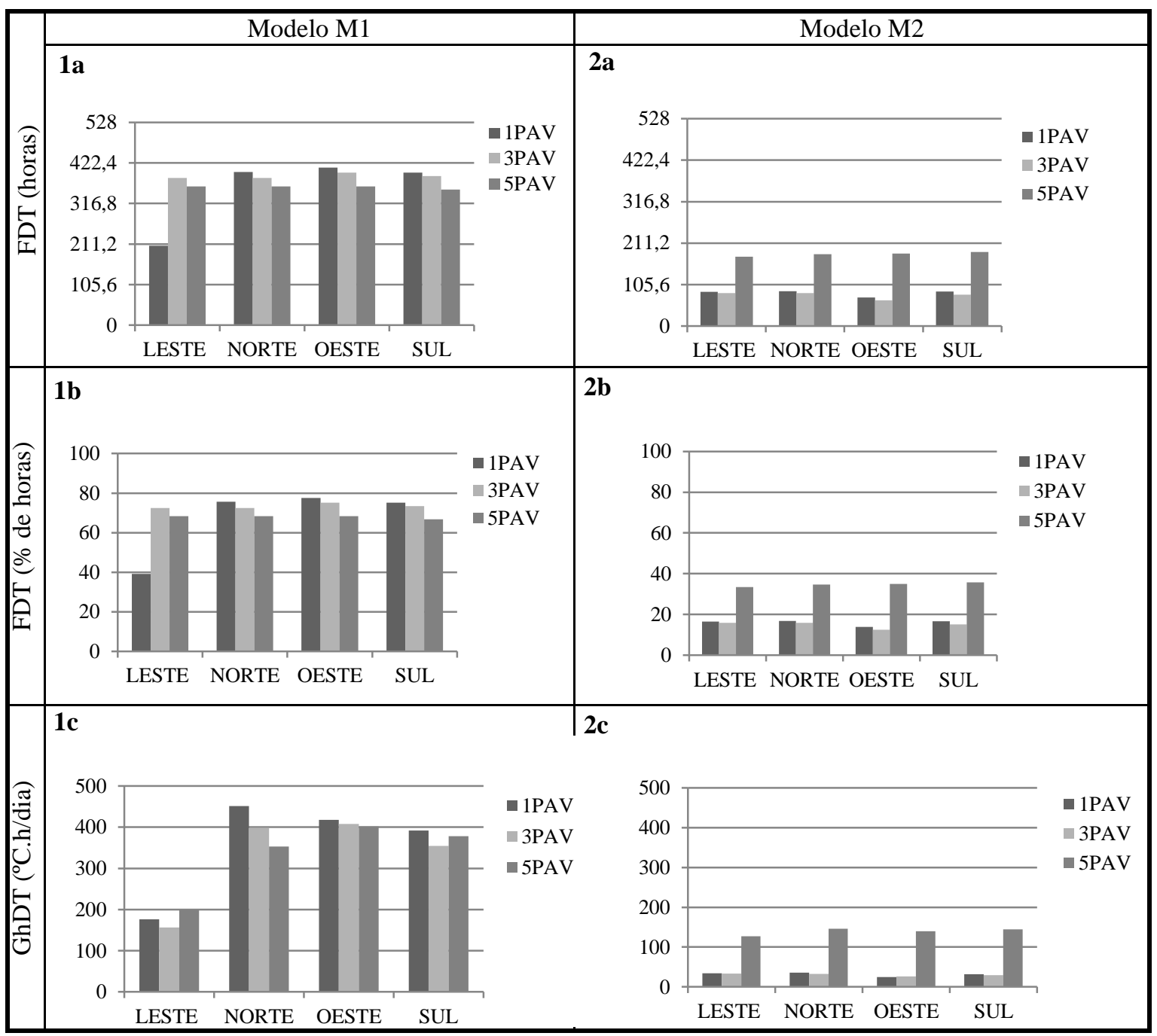

20 Nico-Rodrigues, E. A.; Alvarez, C. E.; Santo, A. D.; Piderit, M. B. 


\section{Considerações finais}

O levantamento de campo realizado na cidade de Vitória, ES, nos bairros com maior crescimento imobiliário, demonstrou que os modelos de janelas com diversos componentes - como controles independentes, elementos permeáveis e proteções solares - são observados nos edifícios mais antigos. Esses modelos de janelas possuem normalmente maiores dimensões e são elementos essenciais para possibilitar o melhor desempenho do ambiente. O levantamento de campo permitiu ainda identificar que o tipo mais comumente utilizado na região escolhida é resultante de um processo construtivo que induz à utilização de componentes construtivos com propriedades que não favorecem um desempenho melhor, com graves consequências no conforto térmico.

Em relação ao método de avaliação proposto, baseado na metodologia sugerida por Sicurella, Evola e Wurtz (2012), a adoção de uma abordagem estatística que introduz dois indicadores para frequência e para a quantidade de graus-horas de desconforto torna-se inovadora, pois permite visualizar de forma conjunta ou separadamente os indicadores, avaliando as condições de ambientes com soluções construtivas diferentes, ou mesmo as situações atuais, determinando a condição de conforto para ele.

Ressalta-se que a abordagem é indicada para ambientes ventilados naturalmente, pois utiliza o conceito de conforto adaptativo da ASHRAE 55, com as devidas restrições definidas na normativa.

Após a definição dos condicionantes e parâmetros necessários para as simulações, o método adotado foi utilizado objetivando analisar o desempenho do ambiente com o uso de tipos de janelas para edificações multifamiliares em Vitória, com foco no conforto térmico. Os indicadores permitiram um entendimento das condições internas do ambiente, com base nas flutuações diárias da temperatura operativa, orientando para a adoção de soluções adequadas para a melhoria do conforto final para o usuário.

A análise do levantamento de campo demonstrou que os tipos de janelas utilizados na maioria das edificações multifamiliares localizadas nos bairros com maior crescimento imobiliário não possuem componentes como venezianas e persianas. Estes elementos possibilitam maior uso da ventilação com o objetivo de minimizar o efeito das temperaturas internas mais elevadas, salientando que outros fatores, como as propriedades térmicas dos materiais da envoltória, também são importantes.
No entanto, esta pesquisa ateve-se à influência do tipo de janela no desempenho do ambiente, considerando as técnicas construtivas normalmente adotadas na região. Os resultados demonstraram que o modelo comumente utilizado não é adequado às condições climáticas de Vitória, visto que a ausência de componentes permeáveis à ventilação e dispositivos de sombra são alguns dos fatores essenciais para a definição de condições mais confortáveis termicamente.

As condições internas com o uso do modelo M2 demonstraram que a orientação oeste e o $3^{\circ}$ pavimento obtiveram melhores condições de desempenho, e com o modelo M1 a mesma orientação teve o pior resultado. Esses resultados demonstraram a necessidade de utilização de componentes mínimos para amenizar a influência da radiação solar no ambiente interno e possibilitar a ventilação constante por um período maior, mesmo não sendo a orientação do vento mais frequente nesse período.

Os resultados demonstrados pelo uso do modelo M2 confirmaram a necessidade de janelas que permitam controlar a ventilação e elementos para proteger da incidência solar nos períodos mais quentes. $\mathrm{O}$ alcance das melhorias foi substancialmente importante para consolidar as premissas descritas pelas diretrizes bioclimáticas mencionadas na literatura.

A proposta de um método novo para avaliação do desempenho térmico tendo como dados de entrada apenas a temperatura operativa horária para a definição do conforto térmico tem possibilidades de ser utilizada em comparativos de soluções construtivas, ainda na fase de projetos ou mesmo de edificações em uso, como foi o estudo desta pesquisa. Esse método está sendo aplicado pelos autores para definir outros tipos de janelas mais adequadas para a cidade de Vitória, considerando diferentes componentes da janela e da edificação.

\section{Referências}

ALBATICI, R.; PASSERINI, F. Bioclimatic Design of Buildings Considering Heating Requirements in Italian Climatic Conditions: a simplified approach. Building and Environment, v. 46 , n. 8 , p. $1624-1631,2011$.

AMERICAN SOCIETY OF HEATING, REFRIGERATING AND AIR-CONDITIONING ENGINEERS. ASHRAE 55: handbook, Fundamentals. Atlanta, 2004. 
ASSOCIAÇÃO BRASILEIRA DE NORMAS TÉCNICAS. NBR 15575-1: edifícios

habitacionais: parte 1: requisitos gerais. Rio de Janeiro, 2013a.

\section{ASSOCIAÇÃO BRASILEIRA DE NORMAS} TÉCNICAS. NBR 15575-4: edificações habitacionais: parte 4: requisitos para os sistemas de vedações verticais internas e externas. Rio de Janeiro, 2013b.

\section{ASSOCIAÇÃO BRASILEIRA DE NORMAS}

TÉCNICAS. NBR 15220-3: desempenho térmico de edificações: parte 3: zoneamento bioclimático brasileiro e estratégias de condicionamento térmico passivo para habitações de interesse social. Rio de Janeiro, 2005.

\section{ASSOCIAÇÃO BRASILEIRA DE NORMAS} TÉCNICAS. NBR 10820: caixilho para edificação: janela. Rio de Janeiro, 1989.

ASSOCIAÇÃO BRASILEIRA DE NORMAS TÉCNICAS. Projeto de norma - CEE-191. $1^{\circ}$ Projeto 191.000.01-001/6. ABNT/CEE - 191. Parte 6: Esquadrias para edificações - Requisitos e classificação, métodos de ensaio, instalação e manutenção. Rio de Janeiro, 2014.

BITTENCOURT; L.; CÂNDIDO, C. Introdução à Ventilação Natural. 2. ed. rev. e ampl. Maceió: EDUFAL, 2006.

BRASIL. Ministério do Desenvolvimento, Indústria e Comercio Exterior. Instituto Nacional de Metrologia, Normalização e Qualidade Industrial. Portaria n. 449, de 25 de novembro de 2010, que estabelece Requisitos Técnicos da Qualidade para o Nível de Eficiência Energética de Edificações Residenciais (RTQ-R). Rio de Janeiro, 2012a.

BRASIL. Ministério do Desenvolvimento, Indústria e Comercio Exterior. Instituto Nacional de Metrologia, Normalização e Qualidade Industrial. Portaria n. 372, 17 de setembro de 2010, que estabelece Requisitos Técnicos da Qualidade para o Nível de Eficiência Energética de Edificações Comerciais, de serviços e públicos (RTQ-C). Rio de Janeiro, 2012b.

COMITÉ EUROPÉEN DE NORMALISATION.

EN 15251: indoor environmental input parameters for design and assessment of energy performance of buildings addressing indoor air quality, thermal environment, lighting and acoustics. Brussels, 2007.

DESIGNBUILDER. DesignBuilder Software Ltda. Version 3.0.0.105. 2012.
DESIGNBUILDER. DesignBuilder 2.1 User's anual. 2009. Disponível em: <http://www.designbuildersoftware.com/docs/desi gnbuilder/DesignBuilder_2.1_Users-Manual _Ltr.pdf>. Acesso em: 12 jul. 2012.

GUSTAVSEN, A. et al. Key Elements of and Materials Performance Targets for Highly Insulating Window Frames. Energy and Buildings, v. 43, n. 10, p. 2583-2594, 2010.

HUMPHREYS, M. A.; RIJAL, H. B.; NICOL, J. F. Updating the Adaptive Relation Between Climate and Comfort Indoors: new insights and an extended data base. Building and Environment, v. 63 , p. 40-55, 2013.

JONSSON, A.; ROOS, A. Evaluation of Control Strategies For Different Smart Window Combinations Using Computer Simulations. Solar Energy, v. 84, n. 1, p. 1-9, 2010.

KIM, T. J.; PARK, J. S. Natural Ventilation With Traditional Korean Opening in Contemporary House. Building and Environment, v. 45, p. 5157, 2010.

\section{LABORATÓRIO DE EFICIÊNCIA ENERGÉTICA EM EDIFICAÇÕES. Seção} Downloads. Arquivos climáticos em formato EPW. Disponível em:

<http://www.labeee.ufsc.br/downloads>. Acesso em: 2 set. 2012.

LAMBERTS, R.; DUTRA, L.; PEREIRA, F. O. R. Eficiência Energética na Arquitetura. São Paulo: PW, 2004.

MATTIUZZI, H. V.; MARCHIORO, E. O Comportamento dos Ventos em Vitória (ES): a gestão e interpretação dos dados climatológicos. Revista Geonorte, v. 2, n. 4, p. 983-993, 2012.

MERMET, A. G. Ventilación Natural de Edifícios. Buenos Aires: Eduardo Yarke; Nobuko, 2005.

NICO-RODRIGUES, E. A. Janelas x Ventilação: modelo de apoio à escolha para edificações multifamiliares em Vitória, ES. Vitória, 2008. 177 f. Dissertação (Mestrado em Engenharia Civil) Escola de Engenharia, Universidade Federal do Espírito Santo, Vitória, 2008.

NICOL, J. F.; HUMPHREYS, M. A. Adaptive Thermal Comfort and Sustainable Thermal Standards For Buildings. Energy and Buildings, v. 34, n. 6, p. 563-572, 2002.

PREFEITURA MUNICIPAL DE VITÓRIA. Código de Obras da Prefeitura Municipal de Vitória. Vitória, 1998. 
ROAF, S.; FUENTES, M.; THOMAS, S.

Ecohouse: a casa ambientalmente sustentável. 2. ed. Porto Alegre: Brookman, 2006.

SADINENI, S. B.; MADALA, S.; BOEHM, R. F. Passive Building Energy Savings: a review of building envelope components. Renewable and Sustainable Energy Reviews, v. 15, n. 8, p. 36173631, 2011.

SANTO, A. D.; ALVAREZ, C. E.; NICORODRIGUES, E. A. Conforto e Desempenho Térmico em Contradição na NBR 15575. Cadernos PROARQ 20, v. 20, p. 116-136, 2013.

SILVA, N. N. de. Amostragem Probabilística. São Paulo: EDUSP, 1998.

SICURELLA, F.; EVOLA, G.; WURTZ, E. A Statistical Approach For the Evaluation of Thermal and Visual Comfort in Free-Running Buildings. Energy and Buildings, v. 47, p. 402-410, 2012.

\section{SINDICATO DA INDÚSTRIA DA CONSTRUÇÃO CIVIL NO ESTADO DO ESPÍRITO SANTO. Sinduscon-ES. Censo} Imobiliário. Disponível em: <http://www.sinduscon-es.com.br>. Acesso em: 10 jul. 2011.

SORMAN, A. H.; GIAMPIETRO, M. The Energetic Metabolism of Societies and the Degrowth Paradigm: analyzing biophysical constraints and realities. Journal of Cleaner Production, v. 38, p. 80-93, 2013.

STAVRAKAKIS, G. M. et al. Optimization of Window-Openings Design For Thermal Comfort in Naturally Ventilated Buildings. Applied

Mathematical Modelling, v. 36, n. 1, p. 193-211, jan. 2012.

\section{Agradecimentos}

Ao Programa de Pós-Graduação em Arquitetura e Urbanismo da Universidad del Bío-Bío, Concepción, Chile.

\section{Cristina Engel de Alvarez}

Departamento de Arquitetura e Urbanismo, Centro de Artes | Universidade Federal do Espírito Santo | Tel.: (27) 4009-2581 |

E-mail: cristinaengel@pq.cnpq.br

\section{Amábeli Dell Santo}

Coordenadoria de Arquitetura e Urbanismo | Instituto Federal do Espírito Santo | Av. Arino Gomes Leal, 1700, Santa Margarida | Colatina - ES - Brasil | CEP 29700-558 | Tel.: (27) 3717-0422 | E-mail: amabeli.dellsanto@ifes.edu.br

\section{Maria Beatriz Piderit}

Facultad de Arquitectura, Construcción y Diseño | Universidad del Bío-Bío | Av. Collao, 1202 | Concepción - Chile | Tel.: +56 (41) 311 1409 | E-mail: mpiderit@ubiobio.cl

\section{Revista Ambiente Construído}

Associação Nacional de Tecnologia do Ambiente Construído

Av. Osvaldo Aranha, $99-3^{\circ}$ andar, Centro

Porto Alegre - RS - Brasil

CEP $90035-190$

Telefone: +55 (51) 3308-4084

Fax: +55 (51) 3308-4054

www.seer.ufrgs.br/ambienteconstruido

E-mail: ambienteconstruido@ufrgs.br 